\title{
Burkholderia glumae and B. gladioli Cause Bacterial Panicle Blight in Rice in the Southern United States
}

Rangaraj Nandakumar, Department of Plant Pathology and Crop Physiology, Louisiana State University Agricultural Center, Baton Rouge 70803; A. K. M. Shahjahan, Baton Rouge Community College, Baton Rouge, LA 70806; X. L. Yuan, Department of Plant Pathology and Crop Physiology, LSU-Agcenter, Baton Rouge 70803; E. R. Dickstein, Department of Plant Pathology, University of Florida, Gainesville 32611; D. E. Groth, LSU Agcenter Rice Research Station, Rayne, LA 70578; C. A. Clark, Department of Plant Pathology and Crop Physiology, LSUAgcenter, Baton Rouge 70803; R. D. Cartwright, University of Arkansas, Fayetteville 72701; and M. C. Rush, Department of Plant Pathology and Crop Physiology, LSU-Agcenter, Baton Rouge 70803

\begin{abstract}
Nandakumar, R., Shahjahan, A. K. M., Yuan, X. L., Dickstein, E. R., Groth, D. E., Clark, C. A., Cartwright, R. D., and Rush, M. C. 2009. Burkholderia glumae and B. gladioli cause bacterial panicle blight in rice in the southern United States. Plant Dis. 93:896-905.

Bacterial panicle blight (BPB) is among the three most limiting rice diseases in Louisiana and the southern United States. The identity and characterization of pathogens associated with this disease was unclear. This research details studies carried out on the pathogens causing BPB on rice in Louisiana and other rice producing southern states. Bacterial strains were isolated from BPB-infected sheath, panicle, or grain samples collected from rice fields in Louisiana, Arkansas, Texas, and Mississippi. In greenhouse inoculation tests, 292 of 364 strains were pathogenic on rice seedlings or panicles. Identification of strains in the pathogen complex by growth on S-PG medium, carbon source utilization profile (Biolog), cellular fatty acid analysis, and polymerase chain reaction (PCR) methods revealed that 76 and 5\% of the strains were Burkholderia glumae and $B$. gladioli, respectively. The other strains have not been conclusively identified. Although strains of both species produced similar symptoms on rice, B. glumae strains were generally more aggressive and caused more severe symptoms on rice than $B$. gladioli. Virulent strains of both species produced toxoflavin in culture. The two species had similar growth responses to temperature, and optima ranged from 38 to $40^{\circ} \mathrm{C}$ for B. glumae and 35 to $37^{\circ} \mathrm{C}$ for B. gladioli. PCR was the most sensitive and accurate method tested for identifying the bacterial pathogens to the species level. The 16S rDNA gene and 16S-23S rDNA internal transcribed spacer (ITS) region sequences of the B. glumae and B. gladioli strains from rice showed more than $99 \%$ sequence homology with published sequences. A real-time PCR system was developed to detect and quantify this pathogen from infected seed lots. Our results clearly indicate that B. glumae and B. gladioli were the major pathogens causing BPB in the southern United States.
\end{abstract}

Rice production in the southern United States has a long history of loss to panicle blighting of unknown etiology (7). Epidemics of panicle blight occurred during 1995 and 1998, years of record high nighttime temperatures, with yield losses in some fields estimated to be as high as $40 \%$. Significant losses were also experienced in Louisiana during 2000 (20,30). Earlier, panicle blighting was attributed to abiotic factors including high temperature, water stress, or toxic chemicals near the root zone (7), but in 1996-97, the bacterial plant pathogen Burkholderia glumae (formerly Pseudomonas glumae) was identified as a cause of panicle blighting in the southern United States (30). This bacte-

Corresponding author: M. C. Rush

E-mail: MRush@agcenter.lsu.edu

Accepted for publication 20 May 2009.

doi:10.1094/PDIS-93-9-0896

(C) 2009 The American Phytopathological Society rium was first described in Japan as the cause of grain rotting and seedling blight on rice (6). The disease was later reported from other Asian countries and Latin America $(2,4,10,40)$. B. glumae produces the phytotoxin toxoflavin, which is essential for its virulence. Strains that lack toxin production become avirulent $(9,26)$. The symptoms of bacterial panicle blight (BPB) include seedling blight, sheath rot, and panicle blight with significant yield losses (2,27,34,39). Specific sheath symptoms include long, vertical grayish lesions surrounded by a dark reddishbrown margin (Fig. 1A). The disease is characterized as having upright, strawcolored panicles containing florets with a darker base and a reddish-brown line (margin of lesion) across the floret between the darker area and the strawcolored area, resulting in abortion of the kernel before it fills (Fig. 1B). Severely affected panicles remain upright, as the grain does not fill (Fig. 1C). The term "panicle blight" has been used in the United States for more than 50 years, and
$\mathrm{BPB}$ has been retained as the name for the disease in this country.

As no published reports were available for this disease in North America in 1996 and most of the commercially grown U.S. rice varieties were susceptible to this disease $(22,27,30)$, it was necessary to determine whether $B$. glumae was the pathogen causing BPB, as in Japan and other countries, or if it was part of a pathogen complex. Also, the pathogen was reported as seedborne, and rice crops planted with infected seeds can suffer severe losses $(31,34)$. Oxolinic acid is the only chemical that controls this pathogen; however, oxolinic acid-resistant B. glumae strains have been isolated from rice in Japan (8), and oxolinic acid is not labeled for use on rice in the United States. In this context, use of pathogen-free seeds is an important practice to reduce or manage the incidence of BPB. Therefore, it was essential to develop rapid, sensitive, and inexpensive methods for identifying and quantifying the levels of B. glumae in certified seeds.

Identification of bacterial pathogens based on colony morphology or disease symptoms is difficult and time-consuming $(25,28)$. Final identification must be confirmed with two or more detection methods to ensure that a strain has been identified accurately $(11,24)$. Many biochemical, physiological, and pathological methods have been used to identify and characterize plant-pathogenic bacteria (28). These methods do not identify the pathogens in planta and require pure cultures. However, molecular methods such as real-time polymerase chain reaction (PCR) can be highly sensitive techniques to identify and quantify pathogens both in culture and in planta $(13,15,16,27,29)$. Sequencing of pathogenspecific genes or highly conserved regions such as rRNA or internal transcribed spacer (ITS) regions of RNA is also being used to confirm the identity of pathogen species and to show the diversity within or between species of the same genera $(5,10,14,20,23,27)$.

The objectives of this study were (i) to identify pathogenic bacterial strains from rice with panicle blight, (ii) to determine the role of the different Burkholderia spp. 

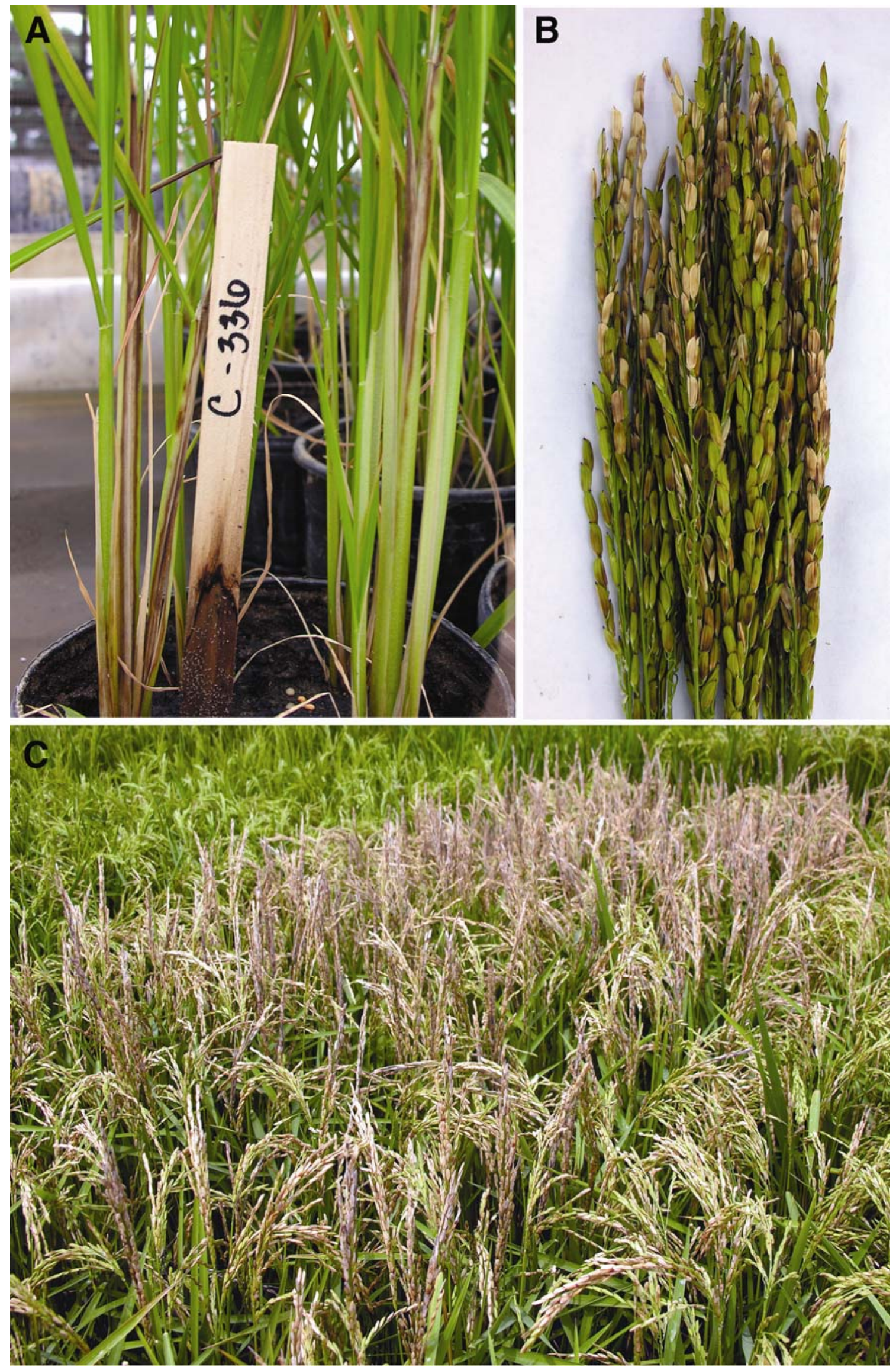

Fig. 1. Symptoms of bacterial panicle blight disease on rice. A, Sheath symptoms: vertical grayish lesion surrounded by dark reddish-brown margin (indicated by arrow). B, Panicle symptoms: straw-colored panicles containing florets with a darker base and a reddish-brown line across the floret between darker straw-colored and straw-colored areas. C, Typical field symptoms of bacterial panicle blight on a susceptible long-grain rice variety (Trenasse) inoculated with Burkholderia glumae. Severely affected panicles remain upright as the grain does not fill. 
associated with blighted rice in the southern United States in causing panicle blight, and (iii) to develop techniques for detecting and quantifying BPB pathogen(s) in infected rice seeds.

\section{MATERIALS AND METHODS}

Isolation and purification of bacterial strains. Bacterial strains were isolated from diseased sheaths and grains showing symptoms of BPB collected from Louisiana, Mississippi, Arkansas, and Texas rice fields using the semiselective S-PG medium (38). These strains were purified by serial dilution, and single colonies were obtained by replating on S-PG medium. Pure cultures of isolates were stored in King's B broth (KBB) (12) with $30 \%$ glycerol at $-70^{\circ} \mathrm{C}$. Fresh cultures were prepared as needed from frozen stock on plates with King's B agar (KBA). American type culture collection (ATCC) strains of the Burkholderia species B. glumae (ATCC 33617 and 49703), B. gladioli (ATCC 51989 and 19302), B. plantarii (ATCC 43733), B. multivorans (ATCC BAA-247), and B. cepacia (ATCC 10856) were used for comparisons.

Pathogenicity tests. Strains were tested for pathogenicity on rice (Oryza sativa L. cv. Cypress) by inoculation at the seedling and heading stages (20 to $30 \%$ panicle emergence). As high temperature predisposes rice plants to $\mathrm{BPB}$, pathogenicity tests were carried out in the greenhouse with daytime temperatures ranging between 37 and $41^{\circ} \mathrm{C}$ and 75 to $95 \%$ relative humidity $(\mathrm{RH})$. Inoculum was grown on $\mathrm{KBA}$ plates incubated at $30^{\circ} \mathrm{C}$ for $24 \mathrm{~h}$, then harvested with a sterile cotton swab and suspended in a vial containing $9 \mathrm{ml}$ of sterile distilled water $\left(10^{7}\right.$ to $\left.10^{8} \mathrm{CFU} / \mathrm{ml}\right)$. Three to five Cypress seedlings at the three- to four-leaf stage were inoculated by injecting the third leaf sheath with $0.5 \mathrm{ml}$ of the bacterial suspension using 1-ml sterile syringes with BD 23G1 needles. Cypress panicles were sprayed with the bacterial suspension as they were emerging (20 to $30 \%$ emerged) from the boot. Sterile distilled water was injected into seedling sheaths or sprayed onto panicles of control plants. Disease reaction was scored on sheaths and panicles of inoculated plants 2 and 4 weeks after inoculation using the four-category disease scale described in Table 1. After disease scoring, bacterial strains were reisolated from diseased plants, to complete Koch's postulates.

Determining temperature optima. Experiments were carried out separately to determine the optimum growth temperatures for B. glumae and B. gladioli. Eight PCR-positive virulent strains and two avirulent strains of $B$. glumae isolated from BPB-infected rice panicles from different fields in Louisiana, Texas, and Arkansas, and 10 strains of B. gladioli isolated from BPB-infected rice panicles from different fields in Louisiana and Arkansas were used. A $100-\mu \mathrm{l}(\mathrm{OD}=1.0)$ culture of each bacterial strain was inoculated into $25 \mathrm{ml}$ of $\mathrm{KBB}$ and incubated at $30,35,40,45$, and $50^{\circ} \mathrm{C}$ on a rotary shaker at $200 \mathrm{rpm}$. Three replications were run for each strain. At 24 and $48 \mathrm{~h}$ of incubation, 2 $\mathrm{ml}$ of bacterial culture was diluted to $8 \mathrm{ml}$ with sterile water, and bacterial growth was measured as absorbance at $600 \mathrm{~nm}$. This experiment was repeated once.

Carbon source utilization and fatty acid analysis of bacterial strains. The ability of strains to use different compounds as sole carbon sources was tested using the Biolog GN2 plates according to manufacture's instruction (Biolog Inc., Hayward, CA). For initial experiments, the plates were read manually and analyzed using Biolog Software. Later, the selected strains were retested and read using the automated Biolog microplate reader
(Biolog Microstation, Biolog Inc., Hayward, CA) and analyzed with Biolog Microlog 1 version 4.01B.

Whole-cell fatty acid analysis of bacterial strains was carried out using the standard extraction procedure for identifying plant-pathogenic bacteria by the MIDI Sherlock Microbial Identification System (25). Extractions and analysis were performed at the Bacterial Identification and Fatty Acid Analysis Laboratory in the Plant Pathology Department at the University of Florida, Gainesville. The fatty acid profiles of our strains were compared with the TSBA50 database. However, there was no entry in the database for B. glumae. To identify our strains, 10 pathogenic $B$. glumae strains, collected from Louisiana, Texas, and Arkansas, that had previously been demonstrated to show positive identifications in PCR, ELISA, and Biolog tests for $B$. glumae, were selected, and their fatty acid profiles were used to construct a library entry for B. glumae using the Sherlock Library Generation System 4.5. The fatty acid profiles of all subsequent bacterial strains from rice were compared with this B. glumae profile.

PCR analyses for ITS region and 16S rDNA. PCR analyses for the 16-23S rDNA ITS regions of $B$. glumae, B. gladioli, and B. plantarii and $16 \mathrm{~S}$ rDNA of B. multivorans were carried out using speciesspecific primers (Table 2). DNA was isolated using Bio-Rad InstaGene Matrix kit for PCR ready DNA isolation (Bio-Rad, Richmond, CA), following the manufacturer's instructions. The respective ATCC

Table 2. Primers used in this study for amplifying internal transcribed spacer (ITS) and 16S rDNA regions of suspected Burkholderia pathogens

\begin{tabular}{|c|c|c|}
\hline Species name & Forward/reverse primers & PCR product size/refs \\
\hline B. glumae & BGF 5' ACACGGAACACCTGGGTA 3' & 400 bp (31) \\
\hline (ITS) & BGR 5' TCGCTCTCCCGAAGAGAT 3' & \\
\hline B. gladioli & BLF 5' CGAGCTAATACCGCGAAA 3' & $300 \mathrm{bp}(5)$ \\
\hline (ITS) & BLR 5' AGACTCGAGTCAACTGA 3' & \\
\hline B. plantarii & BPF 5' AGCCAGTCAGAGGATAAGTC 3' & $200 \mathrm{bp}(31)$ \\
\hline (ITS) & BPR5' CAATTGAGCCGAACATTTAAG 3' & \\
\hline B. multivorans & BMF5' TGTCCGGAAAGAAATCCTTG 3' & 588 bp (this study) \\
\hline 16S rDNA & BMR5' AGCACTCCCGAATCTCTTCA 3' & \\
\hline B. glumae & 16SF 5' AGAGTTTGATCCTGGCTCAG 3' & $1,494 \mathrm{bp}$ (this study) \\
\hline 16S rDNA & 16SR 5' GGCTACCTTGTTACGACTT 3' & \\
\hline
\end{tabular}

Table 1. Scoring system for seedling and panicle blight disease based on symptoms caused by Burkholderia species in greenhouse inoculation tests and numbers of isolated strains falling into each category

\begin{tabular}{|c|c|c|c|c|}
\hline \multirow[b]{2}{*}{ Scale } & \multicolumn{2}{|l|}{ Seedling } & \multicolumn{2}{|l|}{ Panicle } \\
\hline & Symptoms & No. of strains ${ }^{a}$ & Symptoms & No. of strains ${ }^{a}$ \\
\hline 0 & No symptoms produced after inoculation & 96 & No signs of disease on the panicle or florets & 72 \\
\hline+ & Slight browning around the injection site & 73 & Some browning of the florets with most grain & 93 \\
\hline++ & Distinct grayish lesion $1-2 \mathrm{~cm}$ in diameter or & & filling normally & \\
\hline & $\begin{array}{l}\text { spreading up and down from the injection site with } \\
\text { darker brown margin }\end{array}$ & 105 & $\begin{array}{l}\text { Browning on most florets and some grain not } \\
\text { filling, lesions formed on upper most sheath }\end{array}$ & 34 \\
\hline+++ & $\begin{array}{l}\text { Lesion spreading up on the stem from the injection } \\
\text { site with the inner leaf blade yellowing or blighted } \\
\text { and turning necrotic }\end{array}$ & 90 & $\begin{array}{l}\text { covering panicles } \\
\text { Panicles poorly emerging, florets discolored or } \\
\text { with dark brown base with many florets sterile } \\
\text { and panicle tending to remain upright due to lack } \\
\text { of grain filling }\end{array}$ & 165 \\
\hline
\end{tabular}

\footnotetext{
${ }^{a}$ Number of strains observed with each disease reaction from 364 strains.
} 
bacterial cultures of each species served as positive controls. PCR reactions were carried out using Promega master mix (Promega, Madison, WI) in a 25- $\mu$ reaction mixture containing $1 \mu \mathrm{l}$ of total DNA (150 to $200 \eta \mathrm{g}$ ), $12.5 \mu \mathrm{l}$ of $2 \times$ master mix (DNA polymerase, 0.05 unit/ $\mu \mathrm{l}, 3 \mathrm{mM}$ $\mathrm{MgCl}_{2}, 400 \mu \mathrm{M}$ each dNTP), $1 \mu \mathrm{l}$ of each primer (5 pmole of each forward and reverse), and $9.5 \mu \mathrm{l}$ of sterile distilled water. DNA sequences corresponding to the ITS and 16S rDNA regions from the genomic DNA were amplified in a Techne-Genius PCR machine with varying temperature conditions as reported earlier $(5,13,30)$.

PCR reaction of field samples and commercial seed samples. A total of 10 infected florets each from field-collected, naturally infected immature panicles showing BPB symptoms or 20 seeds from commercial seed lots (obtained from the Louisiana State Seed Laboratory) were cut or broken into approximately $0.5-\mathrm{cm}$ pieces, mixed with $3 \mathrm{ml}$ of sterile water, and shaken on a rotary shaker for $2 \mathrm{~h}$ at $200 \mathrm{rpm}$, and then vortexed for $2 \mathrm{~min}$. The bacterial cells were pelleted by centrifugation at $4,350 \times g$ for $10 \mathrm{~min}$. Bacterial DNA was isolated from the pellets as described previously and used in PCR reactions. Seeds were not ground in a mortar to avoid gelling of the pellets by starch from the endosperm.

Cloning and sequencing of $16 S$ rDNA genes and ITS regions. Sequences of both the $16 \mathrm{~S}$ rDNA gene and $16 \mathrm{~S}-23 \mathrm{~S}$ rDNA ITS region were determined for representative $B$. glumae and $B$. gladioli strains collected from Louisiana, Texas, and Arkansas, along with their respective ATCC strain controls. Amplification of the $16 \mathrm{~S}$ rDNA gene was done using 16S rDNA primers (Table 2), and the amplicon was cloned into a pDrive cloning vector (Qiagen, Valencia, CA) according to the manufacturer's instructions. The gene was sequenced using specific primers with the Big Dye Terminator kit (Applied Biosystems, Foster City, CA) and an automated sequencer. For the ITS region, PCR products were gel eluted using Sigma GenEluet agarose spin columns (Sigma, St. Louis, $\mathrm{MO}$ ), concentrated, and used for sequencing. 16S rDNA and ITS sequences of pathogen and ATCC strains were compared with the GenBank database (BlastN 2.2.20). Sequences were aligned using the Multi-align Program to determine similarity percentages.

DNA isolation for real-time PCR. The ATCC 33617 B. glumae strain, our B. glumae strains, and other bacterial cultures isolated in this study (Table 3) were transferred to $\mathrm{KBB}$ and incubated on an orbiting shaker for $18 \mathrm{~h}$ at $200 \mathrm{rpm}$ at $35^{\circ} \mathrm{C}$. Bacterial cells $\left(\mathrm{OD}_{600}=0.5\right)$ were collected from $1 \mathrm{ml}$ of culture by centrifuging at $8,600 \times g$ for $3 \mathrm{~min}$, and pellets were used for DNA isolation. Total genomic DNA was isolated using the Bio-Rad Aq-
uaPure Genomic DNA kit (Bio-Rad) as per the manufacturer's instruction. Simultaneously, the number of CFU in $1 \mathrm{ml}$ of bacterial culture was enumerated by serial dilution and plating on KBA. Three replications were run for both DNA isolation and population count. The quality of DNA was checked on agarose gel and quantified using a NanoDrop ND-1000 spectrophotometer (NanoDrop, Wilmington, DE).

Primer, probe design, and optimization of real-time PCR conditions. Realtime PCR primers and Taqman probe (Applied Biosystems) were designed using Primer3 software based on previously published information (31) (GenBank accession no. D87080) and our B. glumae strains ITS region sequences (accession numbers DQ097385 to DQ097388). The following forward primer: 5' CAAGAT GATTCGAACGCAAGTT $3^{\prime}$; reverse primer: 5' TCGCTCTCCCGAAGAGAT GA 3'; and probe: 5' TACGGCACA AATGCGAGAACTCAACCT $3^{\prime}$ were used for real-time reactions. The Taqman probe was labeled with 6-carboxyfluorescein (FAM) at the 5' end and 6carboxy-tetramethyl-rhodamine (TAMRA) at the $3^{\prime}$ end. Different probe concentrations (50 to $300 \eta \mathrm{M}$ ), primer concentrations $(2.5,5,10,15$, and 20 pmole), and annealing and extension times $(20,30,40$, and $60 \mathrm{~s}$ ) were tested in real-time PCR assays using a uniform template concentration of ATCC B. glumae DNA. The quality of DNA and real-time primer pairs was checked using regular PCR. Real-time PCR was performed using Taqman universal PCR master mix with no AmpErase UNG in an ABI prism 7700 sequence detection system (Applied Biosystems). The 30- $\mu$ l reaction mixture consisted of $15 \mu \mathrm{l}$ of $2 \times$ master mix, $1 \mu \mathrm{l}$ each of forward and reverse primers $(5 \mathrm{pmol} / \mu \mathrm{l}), 1 \mu \mathrm{l}$ of probe $(100 \eta \mathrm{M})$, and varying amounts of DNA template and sterile water. PCR conditions consisted of a 10 -min preincubation period with a 15 -s denaturation at $95^{\circ} \mathrm{C}$ leading to 40 cycles of annealing and extension at $60^{\circ} \mathrm{C}$ for $20 \mathrm{~s}$. In all experiments, the nontemplate DNA control was maintained as a negative control and three replicates were run for each sample.

Standard curve preparation. DNA isolated from the B. glumae ATCC 33671 strain was used for preparing a standard curve. Based on DNA yield from a known quantity of bacterial cells, DNA concentrations of $0.25,2.5,25$, and $250 \mathrm{pg}$ and 2.5 , 25,250 , and 2,500 $\eta \mathrm{g}$, which corresponded to $10^{1}$ to $10^{8} \mathrm{CFU} / \mathrm{ml}$, were used for standard curve preparation. Three replications were used for each concentration. The standard curve was obtained by plotting $\mathrm{Ct}$ (threshold cycle) values of each DNA concentration against the log values of DNA concentration which corresponded to the population (cell number). This was subsequently used for quantifying target bacterial DNA from pure cultures and seed samples with unknown concentrations of pathogen cells.

Real-time PCR identification of bacterial strains and quantification of bacteria from seed samples. DNA isolated from $1 \mathrm{ml}$ of B. glumae (ATCC 33617) solution $\left(\mathrm{OD}_{600}=0.5\right), 7$ strains of $B$. glumae from this study, B. gladioli (ATCC 19302), Pseudomonas putida, P. aeruginosa, and Agrobacterium sp. were used in real-time PCR to determine the specificity of the probe and primers among species of the same genus or from other genera. Naturally infected panicle samples from grower rice fields and samples of certified rice seed from the Louisiana State Seed Laboratory were used in tests to quantify pathogenic bacteria. Infected seed samples $(1,2,5$, or 10 seeds/sample) were broken into $0.5-\mathrm{cm}$ pieces, transferred into small vials containing $3 \mathrm{ml}$ of sterile distilled water, vortexed for $2 \mathrm{~min}$, and incubated at $39^{\circ} \mathrm{C}$ at $200 \mathrm{rpm}$. After $2 \mathrm{~h}$, the vials containing seed suspensions were vortexed for $2 \mathrm{~min}$ and $1 \mathrm{ml}$ of seed suspension was withdrawn to isolate the genomic DNA using a Bio-Rad AquaPure Genomic DNA kit. After checking the quality and quantity of DNA, an equal quantity of DNA from each sample was used for real-time PCR. Three replicates were used for each seed sample. Ct values were compared with the standard curve to estimate bacterial populations in seed samples.

\section{RESULTS}

Isolation and identification of Burkholderia species. A total of 420 bacterial strains were isolated from BPBinfected rice sheath and panicle samples collected from the southern United States during the 1995 to 2004 seasons, including 315,72 , and 33 strains from Louisiana, Arkansas, and Texas, respectively. One $B$. glumae strain was isolated in 2006 from a disease sample obtained from Mississippi. The colony characters of these strains were compared with ATCC strains of several Burkholderia species. Most rice strains were similar in colony characteristics on SPG medium, having circular, smooth, opalescent, convex type colonies with a purple center as previously described (38). The Burkholderia colonies were nonfluorescent under UV light and produced a yellow pigment on KBA.

Pathogenicity tests. Pathogenicity tests revealed that 292 strains $(80 \%)$ of the 364 strains tested were pathogenic on either rice panicles or seedlings. Eighty-eight percent (258 of 292) of the strains caused symptoms typical of panicle blight (Table 1). Seventy-two $(25 \%)$ of the pathogenic strains were highly virulent, with typical symptoms on both seedlings and panicles (Table 1), while $93(31 \%)$ of the strains caused severe symptoms only on inoculated panicles. The remaining strains produced weak to moderate symptoms either on seedlings or panicles. Most of the 
pathogenic strains (>234) were in the genus Burkholderia. Symptoms were only produced by Burkholderia strains identified as $B$. glumae and $B$. gladioli. The symptoms induced by $B$. glumae and $B$. gladioli were similar, and it was not possible to distinguish between species based on symptoms. Koch's postulates were confirmed by reisolating both $B$. glumae and $B$. gladioli from a few representative disease samples showing typical panicle blight symptoms. Twenty $B$. glumae strains (5\%) were not pathogenic. Pathogenic Burkholderia strains produced a yellow pigment, identified as toxoflavin, while nonpathogenic strains did not.

Temperature optima. A similar pattern of growth was observed over different temperatures among virulent and avirulent strains of $B$. glumae, with different growth rates expressed at 30 and $35^{\circ} \mathrm{C}$, and similar rates at 40 to $50^{\circ} \mathrm{C}$. Growth patterns and rates were very similar among the strains of B. gladioli isolated from diseased rice from different locations in the southern United States. The bacterial populations increased as incubation time increased from 24 to $48 \mathrm{~h}$. None of the $B$. gladioli strains grew at temperatures above $45^{\circ} \mathrm{C}$. Based on these results, the temperature optima ranged between 38 and $40^{\circ} \mathrm{C}$ for $B$. glumae and 35 and $37^{\circ} \mathrm{C}$ for B. gladioli. These results were confirmed with a second experiment.

Biolog GN2 identification. Pure cultures of tested strains (364) were first sub- jected to gram staining and then identified based on carbon and nitrogen substrate utilization in the Biolog GN2 system using manual reading of the Biolog plates. Of these strains, 288 were initially identified as Burkholderia species including B. glumae, B. gladioli, B. multivorans, B. plantarii, B. cocovenenans, and $B$. vietnamiensis. The remaining 76 strains were identified as Pseudomonas species, including known pathogens and nonpathogens, or as belonging to 13 other genera (Table 3 ).

Biolog analyses were then rerun on 15 strains each of the strains identified by manual plate readings as $B$. gladioli, $B$. multivorans, and $B$. plantarii; three strains of $B$. vietnamiensis; two strains of $B$. cocovenenans; and some pathogenic non-

Table 3. Identification of selected bacterial strains isolated from the bacterial panicle blight complex on rice from the southern United States using different methods

\begin{tabular}{|c|c|c|c|c|c|c|c|}
\hline \multirow[b]{3}{*}{ Strain no. ${ }^{\mathbf{a}}$} & \multirow[b]{3}{*}{ Biolog ID } & \multirow{3}{*}{$\begin{array}{l}\text { Origin of } \\
\text { isolate }^{b}\end{array}$} & \multirow{2}{*}{\multicolumn{2}{|c|}{ Pathogenicity ${ }^{\mathrm{c}}$ test }} & \multicolumn{2}{|c|}{ Fatty acid identification ${ }^{d}$} & \multirow[b]{3}{*}{$\mathbf{P C R}^{\mathrm{e}}$} \\
\hline & & & & & \multirow{2}{*}{$\begin{array}{c}\text { MIDI/TSBA } \\
\text { (similarity index) }\end{array}$} & \multirow{2}{*}{$\begin{array}{l}\text { Burkholderia glumae } \\
\text { (similarity index) }\end{array}$} & \\
\hline & & & Seeding & Panicle & & & \\
\hline 80 -gr-1 & B. glumae & LA & +++ & +++ & B. cepacia $(0.116)$ & B. glumae $(0.883)$ & B. glumae \\
\hline $189 \mathrm{gr}-4$ & B. glumae & $\mathrm{TX}$ & +++ & +++ & No match $(0.000)$ & B. glumae (0.799) & B. glumae \\
\hline $99 \mathrm{gr}-4-\mathrm{a}$ & B. glumae & LA & ++ & +++ & No match $(0.000)$ & B. glumae (0.936) & B. glumae \\
\hline $99 \mathrm{gr}-8-\mathrm{a}$ & B. glumae & LA & ++ & +++ & B. cepacia $(0.599)$ & B. glumae $(0.945)$ & B. glumae \\
\hline $99 \mathrm{gr}-7-\mathrm{b}$ & B. glumae & LA & ++ & +++ & B. cepacia $(0.386)$ & B. glumae (0.910) & B. glumae \\
\hline 99 sh-14 & B. glumae & LA & +++ & +++ & B. cepacia $(0.564)$ & B. glumae (0.937) & B. glumae \\
\hline $188 \mathrm{gr}-2$ & B. glumae & AR. & ++ & +++ & B. cepacia $(0.116)$ & B. glumae (0.774) & B. glumae \\
\hline $190 \mathrm{gr}-1$ & B. glumae & $\mathrm{TX}$ & + & +++ & B. серасіа $(0.324)$ & B. glumae (0.948) & B. glumae \\
\hline $324 \mathrm{gr}-2$ & B. gladioli & AR & ++ & +++ & No match $(0.000)$ & B. glumae (0.578) & B. glumae \\
\hline $318 \mathrm{gr}-4$ & B. glumae & AR & ++ & +++ & B. cepacia $(0.684)$ & B. glumae $(0.851)$ & B. glumae \\
\hline $99 \mathrm{sh}-15 \mathrm{a}$ & B. glumae & LA & +++ & +++ & B. cepacia $(0.614)$ & B. glumae (0.944) & B. glumae \\
\hline 99 sh-17 & B. glumae & LA & ++ & +++ & B. cepacia $(0.568)$ & B. glumae $(0.930)$ & B. glumae \\
\hline $366 g r-6$ & B. glumae & AR & ++ & ++ & B. cepacia $(0.591)$ & B. glumae $(0.915)$ & B. glumae \\
\hline $117 \mathrm{~g} 1-7 \mathrm{a}$ & B. glumae & LA & 0 & 0 & B. cepacia $(0.578)$ & B. glumae (0.940) & B. glumae \\
\hline $189 \mathrm{gr}-8$ & B. glumae & $\mathrm{TX}$ & 0 & 0 & B. cepacia $(0.245)$ & B. glumae (0.663) & B. glumae \\
\hline $98 \mathrm{gr}-1$ & B. glumae & LA & 0 & 0 & B. cepacia $(0.769)$ & B. glumae (0.772) & B. glumae \\
\hline $191 \mathrm{sh}-10$ & B. glumae & $\mathrm{TX}$ & 0 & +++ & B. серасia $(0.394)$ & B. glumae $(0.828)$ & B. glumae \\
\hline $117 g 1-11$ & B. glumae & LA & 0 & +++ & B. серасіа $(0.224)$ & B. glumae $(0.934)$ & B. glumae \\
\hline 170 sh-1 & B. gladioli & LA & + & + & B. gladioli $(0.450)$ & No match $(0.000)$ & B. gladioli \\
\hline $217 \mathrm{sh}-1$ & B. gladioli & LA & + & ++ & B gladioli $(0.474)$ & No match $(0.000)$ & B. gladioli \\
\hline 223 gr-1 & B. gladioli & LA & ++ & ++ & B. gladioli $(0.310)$ & No match $(0.000)$ & B. gladioli \\
\hline 223 gr- 2 & B. gladioli & LA & ++ & +++ & B. gladioli $(0.470)$ & No match $(0.000)$ & B. gladioli \\
\hline $238 \mathrm{gr}-3$ & B. gladioli & LA & +++ & ++ & B. gladioli $(0.608)$ & No match $(0.000)$ & B. gladioli \\
\hline $321 \mathrm{gr}-6$ & B. gladioli & AR & ++ & + & B. gladioli $(0.293)$ & No match $(0.000)$ & B. gladioli \\
\hline $372 \mathrm{gr}-1$ & B. gladioli & AR & ++ & +++ & B. gladioli (0.799) & No match $(0.000)$ & B. gladioli \\
\hline $378 \mathrm{~g}-3$ & B. gladioli & $\mathrm{AR}$ & ++ & + & B. gladioli $(0.746)$ & No match (0.000) & B. gladioli \\
\hline $382 \mathrm{gr}-1$ & B. gladioli & AR & +++ & ++ & B. gladioli $(0.455)$ & No match $(0.000)$ & B. gladioli \\
\hline $385 \mathrm{gr}-1$ & B. gladioli & AR & ++ & + & B. gladioli $(0.816)$ & No match $(0.000)$ & B. gladioli \\
\hline 156 sh-1 & $\begin{array}{l}\text { Pseudomonas } \\
\text { resinovorans }\end{array}$ & LA & 0 & 0 & P. stutzeri $(0.518)$ & No match (0.000) & $?$ \\
\hline $25-2$ & P. aeruginosa & LA & 0 & 0 & P. putida $(0.122)$ & No match $(0.000)$ & $?$ \\
\hline $170 \mathrm{gr}-4$ & Agrobacterium sp. & LA & 0 & 0 & A. radiobacter $(0.848)$ & No match $(0.000)$ & $?$ \\
\hline $118 \mathrm{sh}-5$ & Pseudomonas grp2 & LA & 0 & 0 & $\mathrm{NT}$ & NT & $?$ \\
\hline 189 sh-6 & $\begin{array}{l}\text { Acidovorax avenae } \\
\text { subsp. avenae }\end{array}$ & $\mathrm{TX}$ & 0 & 0 & A. avenae-avenae (0.939) & No match $(0.000)$ & $?$ \\
\hline ATCC 33617 & B. glumae & Rice/Japan & NT & NT & B. cepacia $(0.687)$ & B. glumae $(0.715)$ & B. glumae \\
\hline ATCC 49703 & B. glumae & Rice/Japan & NT & NT & B. cepacia $(0.418)$ & B. glumae $(0.880)$ & B. glumae \\
\hline ATCC 51989 & B. gladioli & Human USA & NT & NT & B. gladioli $(0.652)$ & No match $(0.000)$ & B. gladioli \\
\hline ATCC 19302 & B. gladioli & Onion USA & NT & NT & NT & NT & B. gladioli \\
\hline ATCC 43733 & B. plantarii & Rice/Japan & NT & NT & B. gladioli $(0.412)$ & B. glumae $(0.060)$ & B. plantarii \\
\hline ATCC 10856 & B. cepacia & - & NT & NT & B. gladioli $(0.550)$ & B. glumae $(0.158)$ & NT \\
\hline ATCC BAA-247 & B. multivorans & Human Belgium & NT & NT & NT & NT & B. multivorans \\
\hline
\end{tabular}

${ }^{a}$ Bacterial strains were isolated either from sheath (sh) or grains (gr). ATTC = American Type Culture Collection (Manassas, VA, USA).

b Origin of isolate: $\mathrm{LA}=$ Louisiana, $\mathrm{TX}=$ Texas, $\mathrm{AR}=$ Arkansas, or country/host.

c,,++++++ refer to weakly, moderately and highly virulent reactions. $0=$ nonpathogenic; NT $=$ not tested for respective analysis.

${ }^{\mathrm{d}}$ Fatty acid data were first compared with the MIDI data base and later with a newly developed $B$. glumae library. Similarity index in parentheses must be at least 0.50 to be considered as acceptable species identification.

e All the strains were first screened with $B$. glumae primers, and then all negative strains were again retested with $B$. glumae primers, followed by other primers if not identified (B. gladioli, B. plantarii, and B. multivorans). If negative $=$ ?. 
Burkholderia spp., including Pseudomonas pyrrocinia and $P$. tolaasii using an automated Biolog reader. All of the above strains were then identified as $B$. glumae by the Biolog database.

Fatty acid analysis. Initial fatty acid analyses, using the TSBA50 database of the MIDI Sherlock Microbial Identification System (MIDI Inc., Newark, DE), identified most of our B. glumae strains as B. cepacia GC subgroup B (Table 3 ), as the MIDI system did not have an entry for $B$. glumae in its database. Fatty acid profiles of 24 strains matched with the MIDI $B$. gladioli profile. Twelve of these strains did not react with $B$. gladioli speciesspecific primers in PCR, but did react with $B$. glumae primers. Later, fatty acid data of all strains were rerun against the new $B$. glumae library developed in the Bacterial Identification and Fatty Acid Analysis Laboratory, and we found that most of our strains were $B$. glumae with a high similarity index. The rice $B$. glumae library showed no match for PCR positive $B$. gladioli strains or for the other identified bacterial strains including P. aeruginosa, Agrobacterium radiobacter, $P$. stutzeri, and Acidovorax avenae subsp. avenae (Table 3 ).

A dendrogram was generated using fatty acid profiles of 124 strains including all the ATCC Burkholderia species control strains, Burkholderia species isolated from rice in this study, Pseudomonas spp., and other related genera including Acidovorax and Agrobacterium isolated from rice. Most of the Pseudomonas and nonBurkholderia species were clustered (groups A, B, and D), all but three of the $B$. gladioli strains were grouped (group C), and all of the $B$. glumae strains were closely grouped (group E). As this dendrogram was too large to present, 41 representative strains were selected from the original 124 strains tested and used to generate a new dendrogram. These strains accurately reflected positioning of strains in the original. In this dendrogram, all $B$. gladioli and $B$. glumae strains were clustered in separate groups with smaller subgroups showing higher similarities with lesser Euclidean distance and with only distant relationship to related genera, such as Pseudomonas, Acidovorax, and Agrobacterium (Fig. 2).

PCR analyses for ITS region and 16S rDNA. A total of 292 strains, including several Burkholderia species and related species from rice in the southern United States, were screened with species-specific primers for B. glumae, B. gladioli, B. multivorans, and B. plantarii with their respective ATCC strains as controls. Amplicons of expected size were generated from 242 strains with B. glumae primers and 12 strains with $B$. gladioli primers. Except for the type strains of $B$. plantarii (ATCC 43733) and B. multivorans (ATCC BAA247), none of the strains identified as $B$. plantarii or B. multivorans by our initial
Biolog readings reacted with $B$. plantarii or $B$. multivorans primers. Thirty-eight strains did not react with any of the four species-specific primers.

Direct isolation of DNA from a test group of field-collected diseased rice panicles and DNA isolated from commercial seed samples reacted only with $B$. glumae primers. Positive PCR identification from direct isolation of DNA from single infected seeds was also demonstrated (data not shown).

16S rDNA and ITS sequence analysis. Sequence analysis of the $16 \mathrm{~S}$ rDNA gene from four B. glumae strains (336gr-1, 189gr-8, 398gr-3, and 99gr-4b), two $B$. gladioli strains (223gr-1 and 321gr-6), and PCR product sequencing of ITS regions of four strains each of B. glumae (336gr-1, 226gr-1, 99gr-11, and 189gr-4) and $B$. gladioli (223gr-1, S022-2a, 238gr-3, and $321 \mathrm{gr}-6)$, along with the respective type strains, followed by comparison of their nucleotide sequences with the GenBank database, showed more than $99 \%$ sequence similarity with already published $B$. glu- mae and B. gladioli sequences. 16S rDNA and ITS sequences for strains of these two bacterial species have been submitted to GenBank (accession numbers DQ355164DQ355169 and DQ097385-DQ097392, respectively). The $16 \mathrm{~S}$ rDNA sequence alignment results from the rice $B$. glumae and $B$. gladioli strains, using the Multialign program, showed high similarity within each species.

Real-time PCR primer and probe specificity. The quality of designed primers was tested with PCR using different concentrations of primers with DNA from B. glumae (ATCC 33617) (data not shown). As the concentration of primers increased, formation of primer dimers also increased. The lowest concentration (5 pmole) of primers with no primer dimers was selected for real-time PCR assays. There were no differences observed in $\mathrm{Ct}$ values when using different concentrations (50 to $300 \eta \mathrm{mol}$ ) of probe and of annealing and extension times (20,40, and $60 \mathrm{~s})$. The lowest annealing time of $20 \mathrm{~s}$ and 100 ๆmol (final concentration) probe concen-

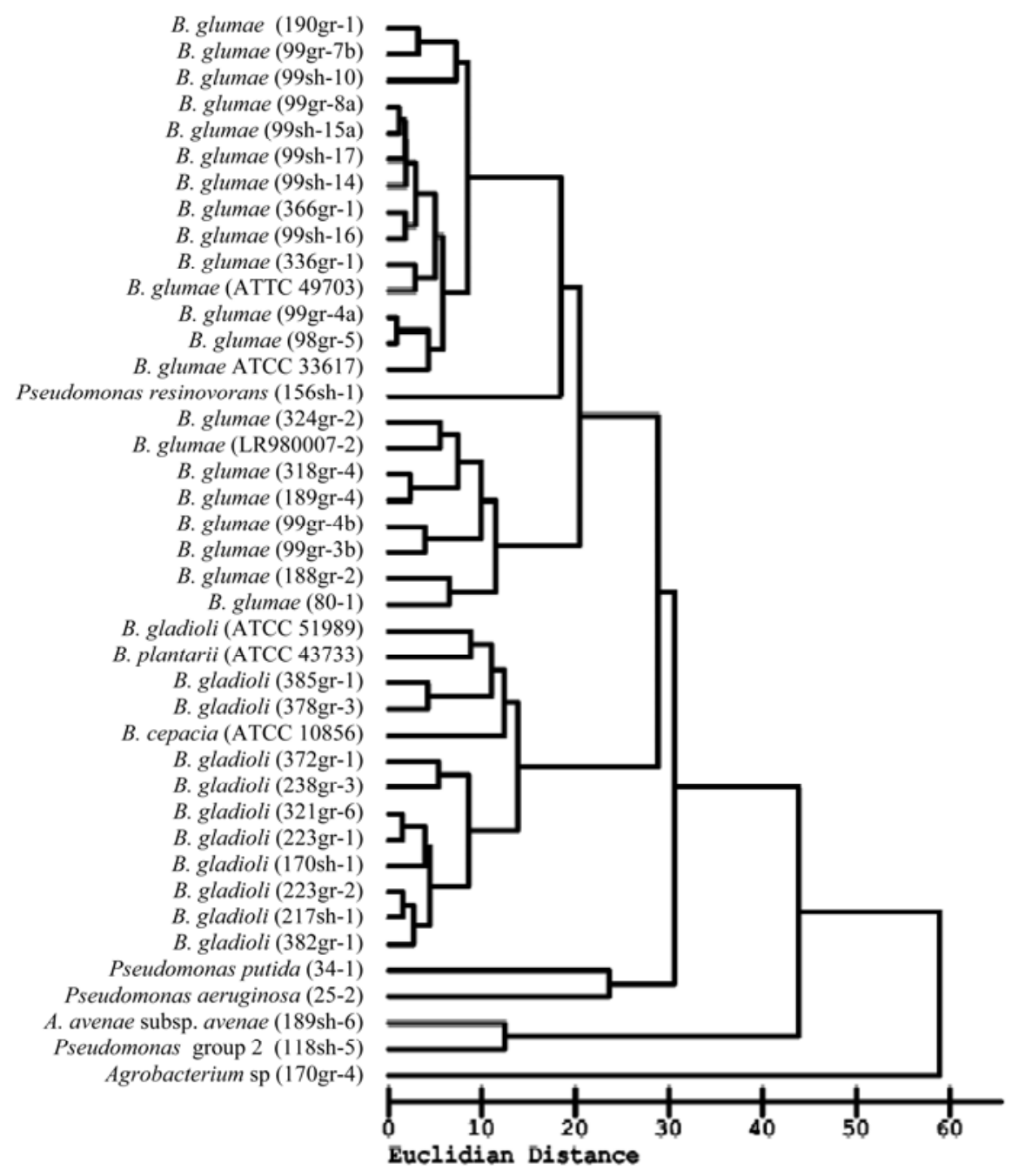

Fig. 2. Dendrogram based on whole-cell fatty acid profiles of selected strains of bacteria isolated from rice showing symptoms of bacterial panicle blight along with 5 ATCC strains of Burkholderia species (MIDI Sherlock microbial identification system database TSBA50 as well as our newly developed $B$. glumae entry library). 
tration was selected as optimum for further assays. The specificity of primers and probe were further tested in real-time PCR, using optimized PCR conditions. DNA isolated from the reference $B$. glumae (ATCC 33617) strain and seven rice $B$. glumae strains (two each from Texas and Arkansas, and three from Louisiana), $B$. gladioli (ATCC 19302), and other related genera Pseudomonas, Acidovorax, and Agrobacterium were tested. Cycle by cycle amplification data showed that the rice strains had the same amplification profile as the B. glumae ATCC 33617 control strain (Fig. 3). No fluorescence or little background signal was noticed until the last cycle for the ATCC B. gladioli and other species, including the nontemplate control.

Standard curve preparation. Realtime PCR assay with a series of known quantities of the reference B. glumae (ATCC 33617) DNA provided a standard curve with a linear relationship between the $\mathrm{Ct}$ values obtained and the log values of known quantities of DNA. A correlation coefficient $\left(r^{2}\right)$ value of 0.98 was obtained (Fig. 4). Detection limits were as low as $10^{1} \mathrm{CFU} / \mathrm{ml}$. By substituting the $\mathrm{Ct}$ values of DNA isolated from B. glumae-infected seed samples, the population level of $B$. glumae could be determined.

Quantification of bacterial populations from seed samples. The bacterial population level was quantified from seed extracts from healthy seeds, panicle blight-infected seed lots, and fieldinfected grain/seed samples. Different seed samples varied in their population levels (Table 4). Of the two known healthy seed samples (lot 1 and lot 2) used for detection, one showed no signal for the presence of bacteria while the other was positive with $260 \mathrm{CFU}$. Three of four samples of certified seed from different rice fields, obtained from the Louisiana State Seed Laboratory, were positive for $B$. glumae (Table 4). Seed from panicles freshly collected in the field tended to show high levels of B. glumae. Samples with varying numbers of seeds (1, 2, 5, and 10 seeds) showed that the pathogen could be detected and quantified from as little as one seed.

\section{DISCUSSION}

This research demonstrated that two pathogenic bacterial species, B. glumae and $B$. gladioli, were the major pathogens routinely isolated from panicle blighted rice collected in the southern rice area of the United States over several seasons. Although rice grain rot, caused by $B$. glumae (formerly Pseudomonas glumae), was initially considered a serious pathogen only in Japan, it is now reported in several major rice growing countries of the world including Korea (10), Taiwan (2), Latin America $(21,40)$, Vietnam (33), the Philippines (3), and the Gulf of Mexico rice production area in the United States $(20,22,27,30)$. The pathogen was reported in 2007 from symptomless seeds in China, where the isolated strain caused disease in inoculated rice plants (17). In addition, $B$. glumae was also reported as the causal agent of bacterial wilt in tomato, eggplant,

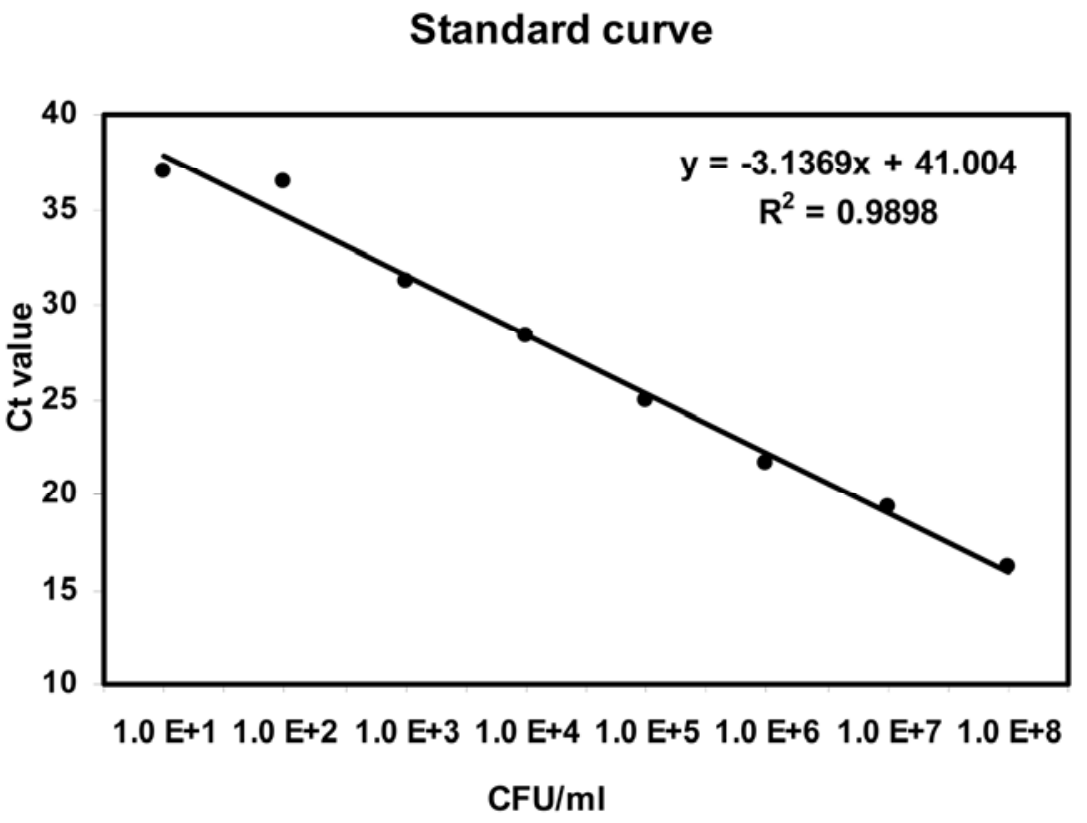

Fig. 4. Standard curve and its correlation coefficient $\left(r^{2}\right)$ were derived by plotting log values of DNA (10-fold dilutions) from $10^{1}$ to $10^{8} \mathrm{CFU} / \mathrm{ml}$ of Burkholderia glumae (ATCC 33617) and threshold cycle $(\mathrm{Ct})$ values obtained in real-time polymerase chain reaction $(\mathrm{PCR})$ for corresponding concentrations. Ct value refers to the PCR cycle number at which $\Delta \mathrm{R}_{\mathrm{n}}$ value crossed the baseline.

\section{Amplification plot}

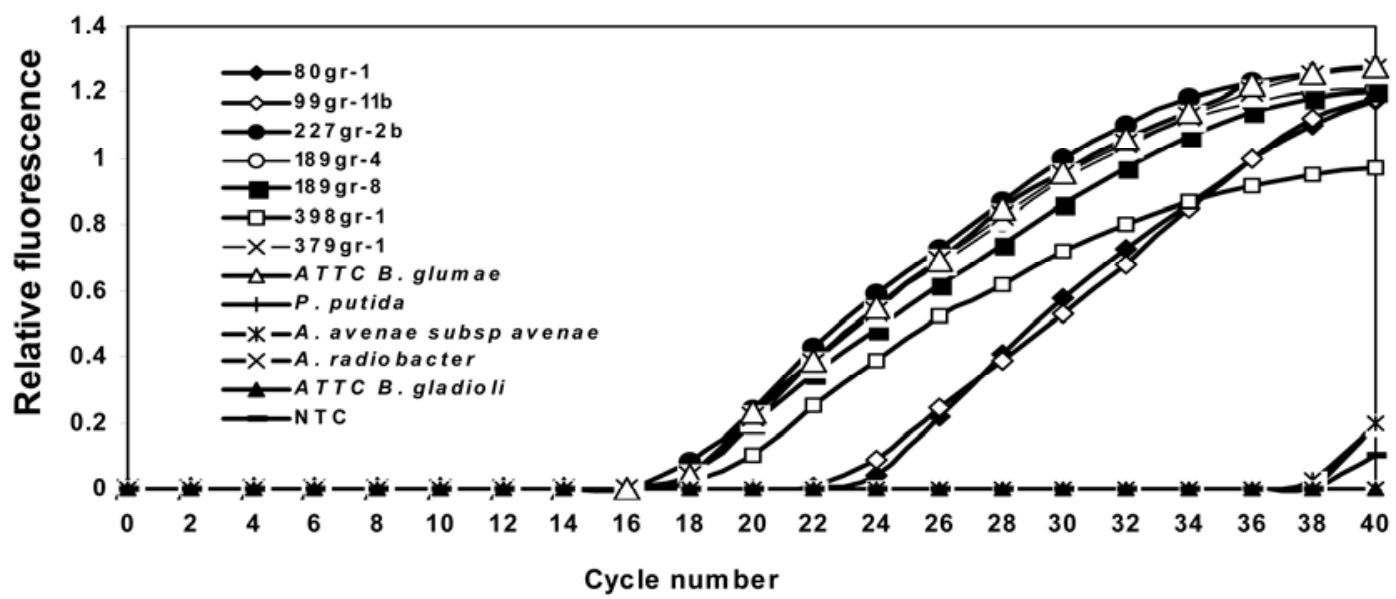

Fig. 3. Real-time polymerase chain reaction (PCR) assay with Burkholderia glumae primers and probe. Relative fluorescence $\left(\Delta \mathrm{R}_{\mathrm{n}}\right)$ of probe obtained in real-time PCR cycle by cycle amplification of seven B. glumae strains, B. glumae (ATCC 33617), B. gladioli (ATCC 19302), and 3 non-Burkholderia genera (Pseudomonas, Acidovorax, and Agrobacterium). No signal was detected for Agrobacterium sp., B. gladioli (ATCC 19302), and nontemplate control (NTC) after 40 PCR cycles. 
hot pepper, potato, sesame, and sunflower in Korea (10).

After a severe epidemic in the southern U.S. rice production area in 1995, the pathogen was identified by our laboratory as B. glumae in 1996 (30). We isolated more than 400 strains of bacteria from infected rice grains in blighted panicles and sheath lesions collected from rice fields in the southern United States during the period 1995 to 2004 . Initial characterization of bacterial strains using various phenotypic characters and the Biolog system suggested that Burkholderia species, including $B$. glumae, might be involved, as they were isolated from virtually all infected tissues plated on S-PG medium. As bacterial panicle blight had not been reported in the United States, and as some isolated species had not been reported as pathogens on rice, we thought it necessary to thoroughly identify the strains by using a broad array of methods. Use of a semiselective medium, fatty acid analysis, species-specific PCR, and sequencing of the $16 \mathrm{~S}$ rDNA and ITS regions of $16 \mathrm{~S}-23 \mathrm{~S}$ rDNA allowed us to identify the most prevalent bacterial pathogen from blighted rice as $B$. glumae and to show that $B$. gladioli was also a cause of the disease, but of less importance (22). In a recent paper, B. gladioli was also reported as a cause of seed rotting in Japan (39).

$\mathrm{BPB}$ has the potential to reduce the yield of rice by as much as $75 \%$ in severely affected rice, as it causes several types of damage, including inhibition of seed germination, seedling blight, sheath rot, floret sterility, and grain abortion $(2,10,20,34,36,40)$. We observed all of these symptoms in our laboratory, greenhouse, and field tests. In our pathogenicity tests, 165 B. glumae strains were more virulent on panicles than on seedlings. This suggests that panicles in the boot or emerging panicles are more susceptible than four-leaf-stage seedlings, as was also observed in Japan and Taiwan (2,36). Some of our B. glumae strains were avirulent on both seedlings and panicles. Avirulence among strains of bacterial pathogens from rice is common (4). The avirulent strains identified in our study did not produce the yellow-pigmented toxin toxoflavin on KBA. Phytopathogenic species of Burkholderia synthesize a variety of toxins such as toxoflavin, fervenulin, and tropolone (26). Toxoflavin has been shown to be necessary for pathogenicity by Burkholderia, causing both seedling disease and grain rot on rice $(9,10,19)$.

Modern bacterial taxonomy involves analysis of multiple characters, including physiological processes such as carbon source utilization, fatty acid profiles, DNA genotyping and diagnostics, and protein composition $(4,5,11,12,14)$. In our study, all the strains identified as B. glumae by Biolog were placed into B. cepacia GC subgroup B by MIDI (Table 3 ) because the
MIDI system does not include $B$. glumae in its database. In another study, Biolog identified the onion bacterial soft rot pathogen as $P$. fragi, but later it was identified as B. gladioli by fatty acid analysis and $16 \mathrm{~S}$ rDNA sequencing (14), but in this study, reaction of $12 / 24 \mathrm{~B}$. gladioli strains identified by MIDI with $B$. glumae primers, and not with $B$. gladioli primers, questioned the reliability of fatty acid analyses for this group. This kind of variation in fatty acid analysis for bacterial strains associated with rice panicle disease was also experienced by Cottyn et al. (4). After developing a $B$. glumae profile, using U.S. rice strains, and comparing our strains using fatty acid data for dendrogram cluster tree analysis, it was clear that B. glumae and $B$. gladioli were both present as pathogens on blighted rice. Furthermore, the fatty acid profiling results were consistent with the species-specific PCR results, which suggests that the amended fatty acid database with the $B$. glumae library can be safely used for identifying B. glumae.

PCR has been used to identify pathogens causing new diseases and even to differentiate species within the same genus $(5,18,27,31)$. More recently, real-time PCR assays have been used for rapid, accurate, and sensitive identification and quantification of pathogens from infected plant tissues $(15,16,24,29)$. PCR and real-time PCR have been used as the main methods cies from soil, water, infected plants, and mammalian cells $(5,18,21,22,27,32)$. In our study, we screened all of the rice strains with $B$. glumae-specific primers and then screened $B$. glumae-negative strains with B. gladioli-, B. plantarii-, and B. multivorans-specific primers. Our PCR results combined with results from other identification methods suggested that two pathogen species, $B$. glumae $(76 \%)$ and $B$. for identifying several Burkholderia spe-

gladioli (5\%), were the major pathogens causing BPB in infected rice from the southern United States and more recently from Panama (21). ITS region and $16 \mathrm{~S}$ rDNA gene sequence analysis and comparison further confirmed identification of the strains as $B$. glumae or B. gladioli. There were other reports that $B$. gladioli could be isolated from rice $(4,5,21,39)$. Our findings confirm the recent report by Ura et al. (39) from Japan that B. gladioli is involved in the panicle blight disease complex. Recently, Sayler et al. (27) reported the occurrence of B. glumae in the United States. However, their study included a smaller population size of only 29 strains isolated from Arkansas compared to 420 strains from the three major rice growing states of the southern United States. We are presently conducting phylogenetic studies using these strains of $B$. glumae from the United States, ATCC control strains from Japan, and selected strains from Latin America (in cooperation with Fernando Correa from CIAT) to more closely compare relationships and possibly origins of the pathogen.

Infected rice seeds serve as the primary source of inoculum for BPB (34). To prevent the spread of this disease, planting pathogen-free seed is critical, and commercial seed lots should be tested for the presence of these plant-pathogenic bacteria. Damage can be avoided or reduced by not planting seeds with high levels of bacteria. We developed a real-time PCR assay to quantify $B$. glumae from seed samples using Taqman probe and primer designed for the $16 \mathrm{~S}-23 \mathrm{~S}$ rDNA ITS region of $B$. glumae. The specificity of our designed probes and primers indicates that they could be used for identification purposes. Similar approaches have been used for detecting other pathogenic bacteria $(15,16,29)$. Recently, Sayler et al. (27)

Table 4. Detection and quantification of Burkholderia glumae from infected seed lots

\begin{tabular}{|c|c|c|}
\hline No. of seeds tested from each seed $\operatorname{lot}^{\mathrm{a}}$ & Ct values ${ }^{b}$ & Calculated no. of cells ${ }^{c}$ \\
\hline \multicolumn{3}{|l|}{ Seed lot \#1 (cv. Cypress) } \\
\hline No. of seeds 1 & 32.3 & $3.6 \times 10^{4}$ \\
\hline 2 & 31.8 & $5.2 \times 10^{4}$ \\
\hline 5 & 26.3 & $2.9 \times 10^{6}$ \\
\hline 10 & 23.6 & $2.1 \times 10^{7}$ \\
\hline Healthy (10 seeds) & No signal $* *$ & $\mathrm{ND}^{* * *}$ \\
\hline Seed lot \#2 (cv. Bengal) & 39 & $2.61 \times 10^{2}$ \\
\hline Healthy ( 10 seeds) & & \\
\hline $\begin{array}{l}\text { Seed lot \#3 } \\
\text { (Field infected-10 seeds) }\end{array}$ & 22.4 & $5.1 \times 10^{7}$ \\
\hline $\begin{array}{l}\text { Seed lot \#4 } \\
\text { (Field infected-10 seeds) }\end{array}$ & 24.8 & $7.5 \times 10^{6}$ \\
\hline Lot \#5 (10 seeds) & 33.3 & $1.7 \times 10^{4}$ \\
\hline Lot \#6 (10 seeds) & No signal & ND \\
\hline Lot \#7 (10 seeds) & 38 & $5.4 \times 10^{2}$ \\
\hline Lot \#8 (10 seeds) & 35.5 & $3.4 \times 10^{3}$ \\
\hline
\end{tabular}

a Seed lots 1 and 2 were obtained from the LSU Agricultural Center Rice Research Station, Crowley, LA, and 3 and 4 were from commercial field samples. Remaining samples (5 through 8 ) were obtained from the Louisiana State Seed Laboratory.

${ }^{\text {b }} \mathrm{Ct}=$ threshold cycle. $* *$ : No fluorescence signal was detected even after 40 polymerase chain reaction cycles indicating the negative reaction; $* * *$ : not determined.

${ }^{c}$ Numbers of cells were calculated using the formula and taking the $\log _{10}$ value for $\mathrm{Ct}$ value $-y$ (integer)/slope and finally multiplied by dilution factor. 
reported the use of PCR and real-time PCR to identify $B$. glumae from diseased rice tissue using isolates from Arkansas rice and strains provided by our laboratory. Although our PCR assays identified the presence of $B$. glumae in a single seed, real-time PCR quantified the amount of inoculum present in the single seed or even in apparently healthy seeds, indicating that healthy seeds may carry the bacteria without showing BPB symptoms. Recently, $B$. glumae was isolated from symptomless rice seeds in China (17). Quantification of pathogenic bacteria from rice seeds can be used to determine the concentration of inoculum present in a seed lot. It is necessary to demonstrate the minimum number of bacteria necessary to cause severe disease or visible symptoms, but this is complicated by several environmental factors, mainly temperature and physiological condition of the plant. Our assay can also be used to quantify the bacteria present on the leaf sheath or blade, as the early-stage epiphytic bacterial populations were positively correlated with seed rot disease development in the field $(34,37)$. As PCR could also detect dead cells, further confirmation of the bacterial population using other methods is necessary.

In Louisiana, major epidemics of BPB were observed in 1995, 1998, and 2000, years characterized by record high temperatures. Published reports suggested that high temperature favors the development of disease on rice caused by $B$. glumae, especially nights with long duration of high temperature $(20,35,37,38)$. We determined that the temperature optima for growth for $B$. glumae and $B$. gladioli ranged from 35 to $40^{\circ} \mathrm{C}$. This is undoubtedly a factor in disease development in the field. Toxoflavin is not produced by $B$. glumae at temperatures below $28^{\circ} \mathrm{C}$ and is maximally produced at $37^{\circ} \mathrm{C}(19)$. B. glumae and $B$. gladioli strains that did not produce toxoflavin were avirulent $(9,19)$. It's also possible that high temperature predisposes the plant to $\mathrm{BPB}$, as high night-time temperatures lead to higher respiration in plants with increased utilization of photosynthetic products and an exponential decline in enzyme activity resulting from enzyme denaturation as temperatures increase (1).

In conclusion, the identity of the pathogens causing BPB in rice in the United States was determined and confirmed by several methods. Our newly developed $B$. glumae fatty acid library and real-time PCR assay can be used to identify and quantify the bacterial population in both field-infected tissues and commercial seed lots. This will allow growers to avoid planting infected seeds or to treat the seed with disinfectants to reduce pathogen populations, which should greatly reduce losses to Louisiana rice producers and other rice growers in the southern United States. Also, as the pathogens causing BPB in U.S. rice are now clearly determined, control measures can be developed for this devastating disease.

\section{ACKNOWLEDGMENTS}

This research was supported by funding from the Louisiana Board of Regents Support Fund (LEQSF (2001-04)-RD-B-02) and the Louisiana Rice Research Board. We thank Toni Marchetti (retired USDA rice pathologist) for sending panicle blight infected rice samples from Texas, Dwight G. Kantor, Agronomist and Rice Breeder, Delta Research and Extension Center, Stoneville, MS for sending a BPB sample from Mississippi, and the Louisiana State Seed Laboratory for samples of certified seed from Louisiana rice fields.

\section{LITERATURE CITED}

1. Abrol, Y. P., and Ingram, K. T. 1996. Effects of higher day and night temperatures on growth and yields of some crop plants. Pages 123-140 in: Global Climate Change and Agricultural Production. Direct and Indirect Effects of Changing Hydrological, Pedological and Plant Physiological Processes. F. Bazzaz and W. Sombroek, eds. John Wiley \& Sons Ltd., Chichester, England.

2. Chien, C. C., and Chang, Y. C. 1987. The susceptibility of rice plants at different growth stages and of 21 commercial rice varieties to Pseudomonas glumae. J. Agric. Res. China 36:302-310.

3. Cottyn, B., Cerez, M. T., Van Outryve, M. F., Barroga, J., Swings, J., and Mew, T. W. 1996. Bacterial diseases of rice. I. Pathogenic bacteria associated with sheath rot complex and grain discoloration of rice in the Philippines. Plant Dis. 80:429-437.

4. Cottyn, B., Regalado, E., Lanoot, B., De Cleene, M., Mew, T. W., and Swings, J. 2001. Bacterial populations associated with rice seed in the tropical environment. Phytopathology 91:282-292.

5. Furuya, N., Ura, H., Ilyama, K., Matsumoto, M., Takeshita, M., and Takanami, Y. 2002. Specific oligonucleotide primers based on sequences of the 16S-23S rDNA spacer region for the detection of Burkholderia gladioli by PCR. J. Gen. Plant Pathol. 68:220-224.

6. Goto, K., and Ohata, K. 1956. New bacterial disease of rice (brown stripe and grain rot). Ann. Phytopathol. Soc. Jpn. 21:46-47.

7. Groth, D. E., Rush, M. C., and Hollier, C. A. 1991. Rice diseases and disorders in Louisiana. Bull. 828. Louisiana State University Agricultural Center, Baton Rouge.

8. Hikichi, Y., Tsujiguchi, K., Maeda, Y., and Okuno, T. 2001. Development of increased oxolinic acid-resistance in Burkholderia glumae. J. Gen. Plant Pathol. 67:58-62.

9. Iiyama, K., Furuya, N., Takanami, Y., and Matsuyama, N. 1995. A role of phytotoxin in virulence of Pseudomonas glumae Kurita et Tabei. Ann. Phytopathol. Soc. Jpn. 61:470476.

10. Jeong, Y., Kim, J., Kim, S., Kang, Y., Nagamatsu, T., and Hwang, I. 2003. Toxoflavin produced by Burkholderia glumae causing rice grain rot is responsible for inducing bacterial wilt in many field crops. Plant Dis. 87:890895.

11. Jones, J. B. 1993. Evaluation of the Biolog GN micro plate system for identification of some plant-pathogenic bacteria. Plant Dis. 77:553558.

12. King, E. O., Ward, M. K., and Raney, D. E. 1954. Two simple media for the demonstration of pyocyanin and fluorescein. J. Lab. Clin. Med. 44:301-307.

13. Kokkinos, C. D., and Clark, C. A. 2006. Realtime PCR assays for detection and quantification of sweetpotato viruses. Plant Dis. 90:783788 .
14. Lee, C. L., Lee, J. T., Kwon, J. H., Kim, B. B and Park, W. 2005. Occurrence of bacterial soft rot of onion plants caused by Burkholderia gladioli pv. allicola in Korea. Aust. Plant Pathol. 34:287-292.

15. Lehman, S. M., Kim, W.-S., Castle, A. J., and Svircev, A. M. 2008. Duplex real-time polymerase chain reaction reveals competition between Erwinia amylovora and E. pyrifoliae on pear blossoms. Phytopathology 98:673-679.

16. Li, W., Li, D., Twieg, E., Hartung, J. S., and Levy, L. 2008. Optimized quantification of unculturable Candidatus Liberibacter spp. in host plants using real-time PCR. Plant Dis. 92:854861.

17. Luo, J., Xie, G., Li, B., and Lihui, X. 2007. First report of Burkholderia glumae isolated from symptomless rice seeds in China. Plant Dis. 91:1363.

18. Mahenthiralingam, E., Bischof, J., Byrne, S. K., Radomski, C., Davies, J., AV-Gay, Y., and Vandamme, P. 2000. DNA-based diagnostic approaches for identification of Burkholderia cepacia complex, Burkholderia vietnamiensis, Burkholderia multivorans, Burkholderia stabilis and Burkholderia cepacia genomovars I and III. J. Clin. Mirobiol. 38:3165-3173.

19. Matsuda, I., and Sato, Z. 1988. Relations between pathogenicity and pigment productivity in the casual agent of bacterial grain rot of rice. Ann. Phytopathol. Soc. Jpn. 54:378.

20. Nandakumar, R., Bollich, P. A., Shahjahan, A K. M., Groth, D. E., and Rush, M. C. 2008. Association of soilborne Burkholderia gladioli with rice sheath rot and panicle blight symptoms. Can. J. Plant Pathol. 30:148-154.

21. Nandakumar, R., Rush, M. C., and Correa, F. 2007. Association of Burkholderia glumae and B. gladioli with panicle blight symptoms on rice in Panama. Plant Dis. 91:767.

22. Nandakumar, R., Rush, M., Shahjahan, A., O'Reilly, K., and Groth, D. 2005. Bacterial panicle blight of rice in the southern United States caused by Burkholderia glumae and $B$. gladioli. (Abstr.) Phytopathology 95:S73.

23. Sahin, F., Abbasi, P. A., Lewis Ivey, M. L., Zhang, J., and Miller, S. A. 2003. Diversity among strains of Xanthomonas campestris pv. vitians from lettuce. Phytopathology 93:64-70.

24. Salm, H., and Geider, K. 2004. Real time PCR for detection and quantification of Erwinia amylovora, the causal agent of fire blight. Plant Pathol. 53:602-610.

25. Sasser, M. 2001. Technical note \#101: Identification of bacteria by gas chromatography of cellular fatty acid analysis. MIDI, Inc., Newark, DE.

26. Sato, Z., Koiso, Y., Iwasaki, S., Matsuda, I., and Shirata, A. 1989. Toxins produced by Pseudomonas glumae. Ann. Phytopathol. Soc. Jpn. 55:353-356.

27. Sayler, R. J., Cartwright, R. D., and Yang, Y. 2006. Genetic characterization and real-time PCR detection of Burkholderia glumae, a newly emerging bacterial pathogen of rice in the United States. Plant Dis. 90:603-610.

28. Schaad N. W., Jones, J. B., and Chun, W. 2001 Laboratory Guide for Identification of Plan Pathogenic Bacteria. 3rd ed. American Phytopathological Society, St. Paul, MN.

29. Schaad, N. W., Opgenorth, D., and Gaush, P. 2002. Real time polymerase chain reaction for one-hour on-site diagnosis of Pierce's disease of grape in early season asymptomatic vines. Phytopathology 92:721-728.

30. Shahjahan, A. K. M., Rush, M. C., Groth, D., and Clark, C. 2000. Panicle blight. Rice J. 15:26-29.

31. Takeuchi, T., Sawada, H., Suzuki, F., and Matsuda, I. 1997. Specific detection of Burkholderia plantarii and B. glumae by PCR using primers selected from the $16 \mathrm{~S}$ 23S rDNA spacer regions. Ann. Phytopathol. 
Soc. Jpn. 63:455-462.

32. Thibault, F. M., Valade, E., and Vidal, D. R. Identification and discrimination of Burkholderia pseudomalleli, B. mallei and B. thailandensis by real time targeting type III secretion system genes. J. Clin. Microbiol. 42:58715874.

33. Trung, H. M., Van, N. V., Vien, N. V., Lam, D. T., and Lien, M. 1993. Occurrence of rice grain rots disease in Vietnam. Int. Rice Res. Notes 18:30.

34. Tsushima, S. 1996. Epidemiology of bacterial grain rots of rice caused by Pseudomonas glumae. JARQ 30:85-89.

35. Tsushima, S., Mogi, S., and Saito, H. 1985.
Effects of inoculum density, incubation temperature and incubation period on the development of rice bacterial grain rot. Proc. Assoc. Plant Prot. Kyushu 31:11-12.

36. Tsushima, S., Naito, H., and Koitabashi, M. 1995. Change in panicle susceptibility associated with flowering rate of spikelets in bacterial grain rot of rice caused by Pseudomonas glumae. Ann. Phytopathol. Soc. Jpn. 61:109113.

37. Tsushima, S., Naito, H., and Koitabashi, M. 1996. Population dynamics of Pseudomonas glumae, the causal agent of bacterial grain rot of rice, on leaf sheaths of rice plants in relation to disease development in the field. Ann. Phy- topathol. Soc. Jpn. 62:108-113.

38. Tsushima, S., Wakimoto, S., and Mogi, S 1986. Selective medium for detecting Pseudomonas glumae Jurita et Tabei, the causal bacterium of grain rot of rice. Ann. Phytopathol. Soc. Jpn. 52:253-259.

39. Ura, H., Furuya, N., Iiyama, K., Hidaka, M. Tsuchiya, K., and Matsuyama, N. 2006. Burkholderia gladioli associated with symptoms of bacterial grain rot and leaf-sheath browning of rice plants. J. Gen. Plant Pathol. 72:98-103.

40. Zeigler, R. S., and Alvarez, E. 1989. Grain discoloration of rice caused by Pseudomonas glumae in Latin America. Plant Dis. 73:368. 